\title{
PEREGRINE
}

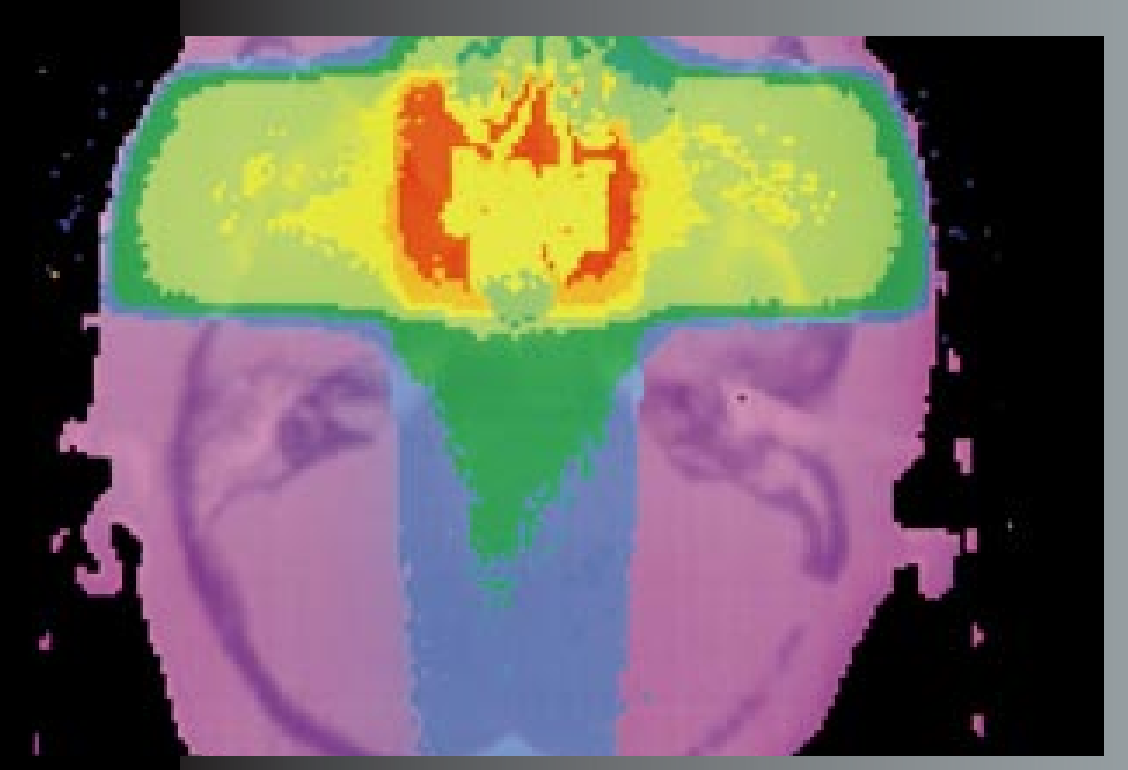

Also in this issue:

- Regenerative Fuel Cells

- Flash X-Ray Upgrades and Gamma-Ray Camera

- Nuclear Weapons Information Project 


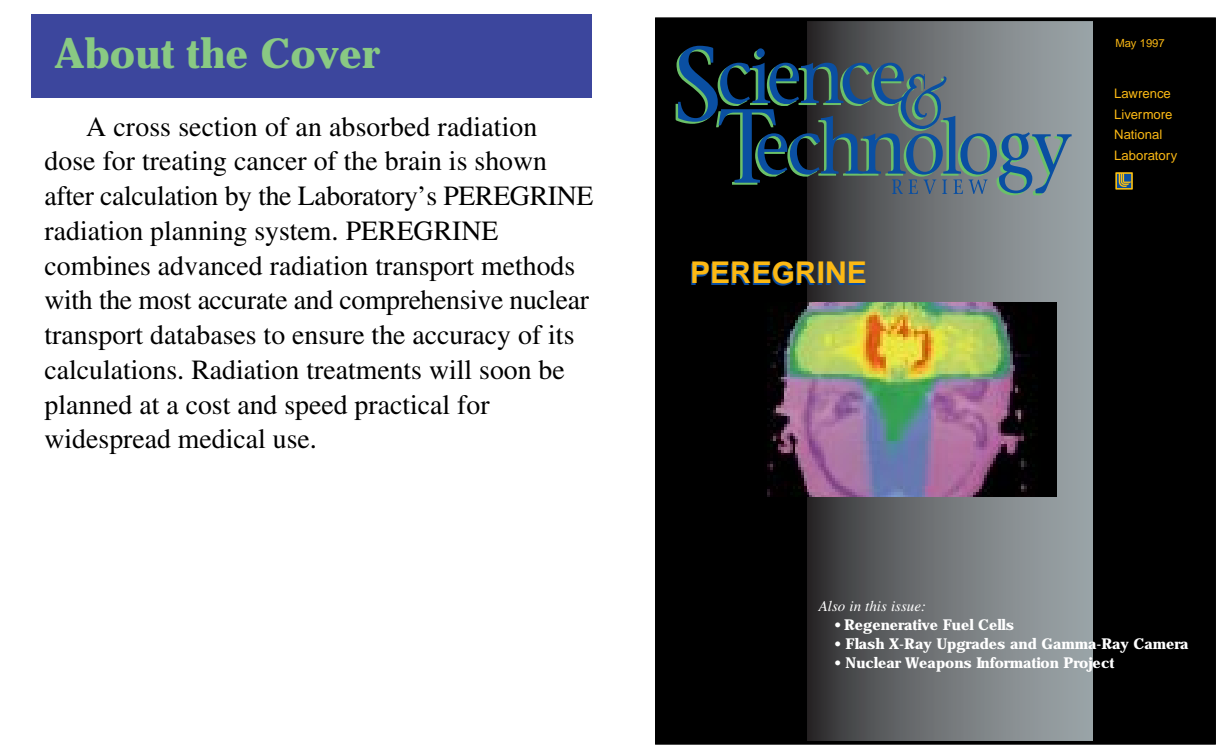

\section{What Do You Think?} publication. Please use the enclosed survey for to give us your feedback.

\section{Electronic Access}

$S \& T R$ is available on the Internet at

hittp:///www.llnl.gov/str. As references become

linked to the footnote references at the end of each article. If you desire more detailed information about an article, click on any reference that is in color at the end of the article, and you will conneci

\section{About the Review 띤}

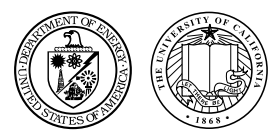

Lawrence Livermore National Laboratory is operated by the University of California for the We also apply that expertise to solve other important national problems in energy, bioscience, and the audience, the Laboratory's scientific and technological accomplishments in fulfiliting its primary missions.

name and address changes) to S\&TR, Mail Stop L-664, 422-8961. Our electronic mail address is hunterø@ lnll.gov. environment. Science \& Technology Review is published ten times a year to communicate, to a broad Lawrence Livermore National Laboratory, P.O. Box 808, Livermore, California 94551, or telephone

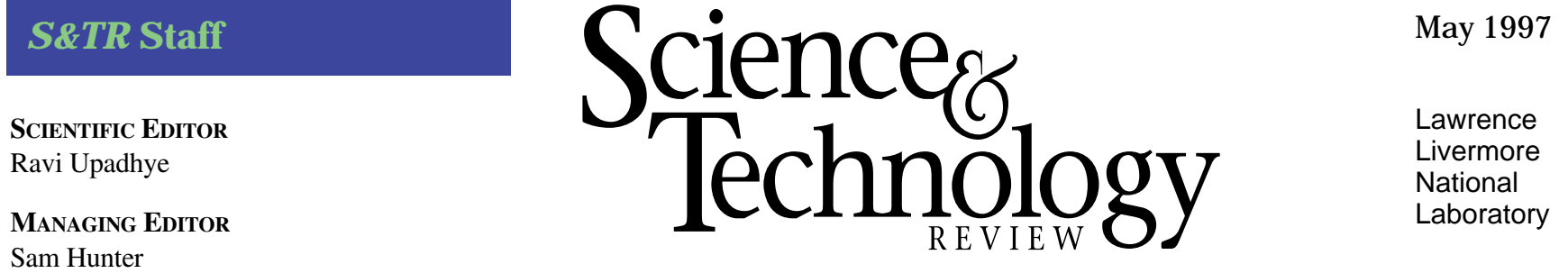

Publication Eotro

Sue Stull

Sam Hunter, Sue Stull, and Katie Walter

ART DIRECTOR

Kitty Tinsley

DESIGNERS

Ray Marazzi and Kitty Tinsley

INTERNET DesigNeR

Kitty Tinsley

CoMpostror

Louisa Cardoza

ProOfReAder

Al Miguel

$S \& T R$ is a Director's Office publication

$S \& T R$ is a Director's Office publication
produced by the Technical Information Department, under the direction of the Office of Policy, Planning, and Specia Studies.

2 The Laboratory in the News

3 Commentary by Edward Moses

Feature

4 PEREGRINE: Improving Radiation Treatment for Cancer A new, all-particle, Monte Carlo calculation system for treating cancer may save thousands of lives. Fast and affordable, the Livermore-developed system will improve present treatment and open the way to new, aggressive radiation treatment method

Research Highlights

12 The Unitized Regenerative Fuel Cell

15 Better Flash Radiography Using the FXI

18 Nuclear Weapons Information Project

20 Patents

Available from

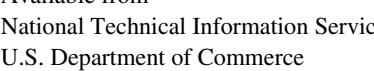

5285 Port Royal Road

UCRL-52000-97-5

Distribution Category UC-700
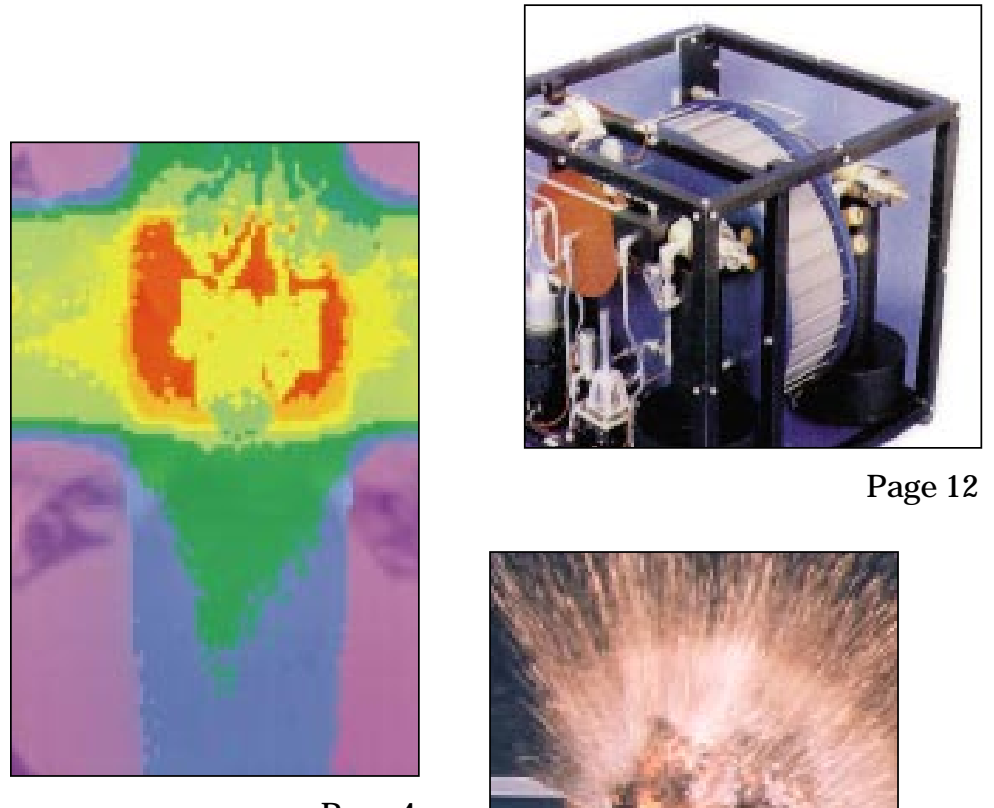

Page 12

Page 4

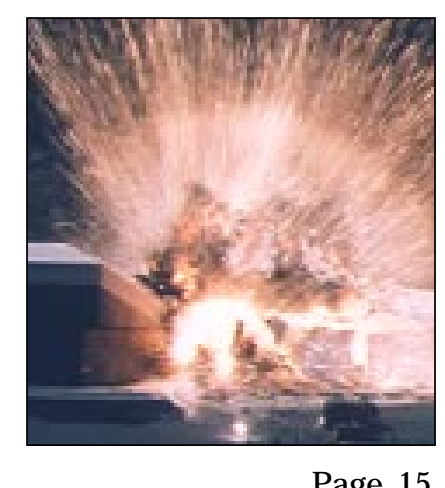


Defense research yields commercial benefits Defense research at Lawrence Livermore may help U.S. companies get a head start in the fiercely competitive international computer chip market, according to Dena Belze author of a new study about the Laboratory's effect on the economy.

Belzer, a principal consultant with Bay Area Economics in Berkeley, quoted industry giants Intel Corp. and Microsoft as saying that breakthroughs at Lawrence Livermore have been critical to putting more information onto tiny microchips. The companies said the Laboratory's cutting-edge research tools and large pool of scientists from diverse disciplines enabled microchip breakthroughs like extreme ultraviolet (EUV) lithography, a technique for putting information on chips tha will allow manufacturers to write on the chips with more thousandth the width of

Belzer's report said that the planned National Ignition Facility laser could pu tect "conomic benefits can only be realized if the nautioned labs continue to have strong interactive relationships with private industry."

Contact: LLNL Media Relations (510) 422-4599

(garberson1@IInl.gov).

Lab seeks source of mystery gamma-ray bursts A telescope developed at Livermore and housed at its Site 300 research center in San Joaquin County, California, is scouring the heavens in search of answers to one of the great mysteries of the universe-gamma-ray bursts. Detected approximately once a day by orbiting satellites, the flashes of gamma rays of unknown origins reach peak energy in a few hun

The telescope, called the Livermore Optical Transient Imaging System (LOTIS), was developed to help reveal clues about the origins of the bursts by searching for light flashes that may accompany them. The telescope consists of a high-resolution, wide-field-of-view system on a mount designed for rapid response and movement. LOTIS has an 18 -degree field of view, The system relies on the orbiting Compton Gacal telescope. The system relies on the orbiting Compton Gamma-Ray bet relayed to Site 300.

The gamma-ray burst research is being conducted in collaboration with NASA's Goddard and Marshall Spece Centers, the University of Californi at San Diego, and Clemson University.

Contact: Hye-Sook Park (510) 422-7062 (park1@|ln. gov).
Predicting floods more accurately Winter floods that swept across northern California in December and January provided proof that the Laboratory's Regional Climate System Model works. Using this systemwhich includes elevation, topography, soils, vegetation, and forecasted weather variables-scientists Norman Miller and Jinwon Kim simulated the Russian River area's sflooding within $85 \%$ of the observed river flow. (See $S \& T R$, July 1995 pp. 28-30, for more information on this work.) Using forecast from the National Weather Service, Miller and Kim predict precipitation at a spatial resolution of 31 square kilometes (12 square miles) to simulate river channel flow. Future plans include adding impacts such as urban development to the nodel, which will give planning organizations help in making critical decisions on water resource, agricultural, and sustainability issues.

Norm Miller (510) 422-3244 (norm@llnl.gov).

Cooper appointed to special technology panel President Clinton named Computation Associate Directo Dave Cooper to the newly formed Advisory Committee on High-Performance Computing and Communications.

Information Technology, and the Next-Generation Internet. The advisory committee will provide guidance and advice on all areas of those fast-changing technologies.

Cooper came to the Laboratory in 1995 after serving as director of information systems at the NASA Ames Researc Center, California. In 1994, he received the NASA Medal fo Outstanding and Exceptional Service for his pioneering in high-performance computing.

Livermore and Savannah River begin collaboration Lowering costs and speeding up development are two of the goals in collaborations of Lawrence Livermore and DOE Savannah River Site. On February 4, Livermore director Bruce Tarter and president of Westinghouse Savannah Rive Co. Ambrose Schwallie signed a memorandum of mutua intent hat outlined technologies involved. They include: disposition of fissile matials, centered on the immobilizatio of plutonium, stabilization of plutonium residue; modular pnduring stockpile; and nonproliferation and arms contro including nucer for monitoring and domestic safegurds. Livermore will be developing and testing ways to stabilize plutonium on a small scale, after which the technology will be transferred to Savannah River, which has larger-scale facilities and experience with large-scale processing and handing of special nuclear materials.

\section{- Using Physics Research to to Help Cure Cancer}

7 HE PEREGRINE program, a new approach to planning for a cure for cancer. This search has been an arduous journey, traceable in recorded history to the ancient Egyptians, who used surgical techniques to remove tumors. The quest has touched many fields of modern science including biology, chemistry, enetics, and-somewhat surprisingly-physics.

In 1895, William Roentgen, a physicist studying electricity and magnetism, discovered x rays. Almost immediately, the abihy or $x$ rays to penetrate many materials and to expose film

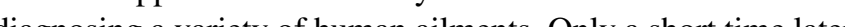
he idea of using x rays to not only "see" cancer, but also to treat it, was being studied.

In the century since this exciting discovery, physicists, engineers, and doctors have been working together to build new types of radiation sources and methods of treatmentstriving to understand how radiation therapy works and how to make it more effective. Today, nearly two million people worldwide are treated with various forms of radiotherapy each year. But like surgery and other forms of treatment, radiotherapy is not without its risks-too little radiation does not destroy the cancer; too much radiation causes damage to healthy tissue. The safety and effectiveness of radiotherapy depend on the accuracy of the treatment, that is, where the radiation is aimed and where its energy is deposited.

This is where PEREGRINE comes into the story.

PEREGRINE brings a radically new level of accuracy to the field of radiotherapy by its unique ability to predict where radiation deposits energy in the body. PEREGRINE will ope the way to more accurate prescriptions for radiation therapy, more aggressive treathont of tumors, lower risk to normal tissue, better clinical trials, and treating cancer.

does the Laboratory bring to his endeavor?
Like Roentgen's discovery of $x$ rays, the development of the PEREGRINE program fits the paradigm of "unexpected consequences." Ironically, much of our knowledge of the physics of radiation that is needed to develop better treatments for cancer- how radiation is produced, how it travels, and how it interacts with various materials-comes from our research into and development of nuclear weapons. Over the last 40 yeas, the Laboratory has developed unmatche
radiation transport and nuclear physics.

radiation transport and nuclear physics. PEREGRINE useful outside a very limited research

environ con beyond proof of principle and put PEREGRINE into the hand of the health-care community. We have melded the Laboratory's core competencies in physics, medical physics, computer science, and engineering to achieve the breakthrough in accuracy, speed, and cost necessary to make PEREGRINE a viable product for medical professionals. We also have established a network of collaborations with the leading medical research institutions in the U.S. to understand and respond to the real needs of their community.

PEREGRINE is now fast enough for everyday use and economical enough to be used in all clinical environments. PEREGRINE may soon help to save lives by bringing

superior radiation treatment to all cancer patients.

The combination of choosing the most difficult problems, building expert multidisciplinary teams to find breakthrough solutions, and working with world experts to complement ou capabilities is the hallmark of successful Laboratory program With this process, we are fulfilling our charter to shape the

- Edward Moses is the Director for Programs in the Physics and Space Technology Directorate. 


\section{PRREGINE}

\section{Improving Radiation}

\section{Treatrent for Cancer}

PEREGRINE “. . . is a unique system of enormous value to society in terms of improving local control and reducing complications in radiation treatment of cancer.' are considered curable because their tumors are localized and susceptible to radiation. Yet, despite the use of the bes radiation therapy methods available, about one-thrid of hese "criable" parents-nealy 120,000 people each at the original site.

Why does this occur? Experts in the ield have looked at the reasons for these fil have looked act he reasons for the therapy planning is often inadecuate, providing either too little radiation to the tumor for a cure or too much radiation to nearby healthy tissue, which results in complications and sometimes death. What can be done to improve this combined its renowned expertise and decades of experience in nuclear scien adiation transport, computer science, Mrente Carlo techiques to a better Men for radiation dose calculations. sycter hysicists Bill Chandler and Roger White, and armed with seed money from Livermore's Laboratory Directed Research and Development medical hysicist Christeve Siment, medicar directing a small project to develo prognosis? Since 1993, Lawrence Livermore National Laboratory has and engineerithg to adapt nuclear weap
PEREGRINE Breakthrough PEREGRINE breaks the barriers to accurate dose calculation with the
full-physics model of the radiation

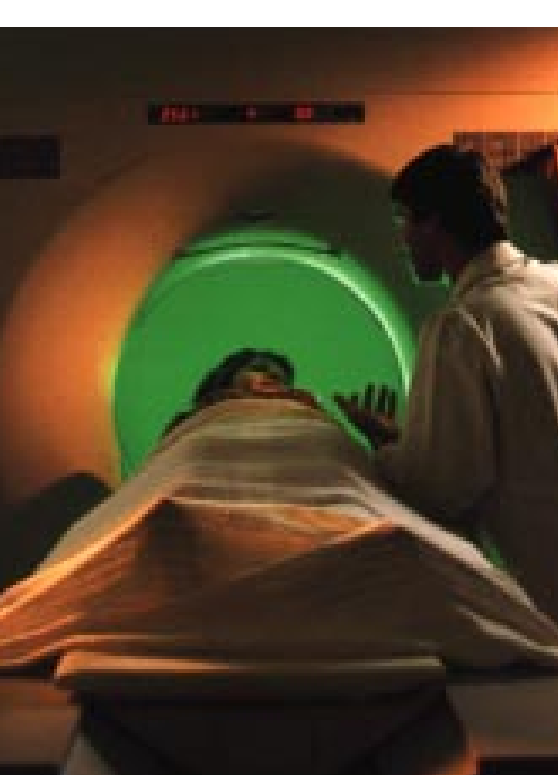

reatment process. It uses Monte Carlo probabilistic approximation of probabilistic approximation of a
problem's solution. This enables PEREGRINE to model how trillions of radiation particles interact with the complex tissues and structures in the human body and where they deposit their energy. In the past, Monte Carlo calculations, known to be the best way to model these interactions, would have required days or weeks of supercomputer resources-impractical for radiation treatment planning. The PEREGRINE team has designed and built the Monte Carlo system to plan accurate radiation treatments at a cost and speed practical for widespread medical use. PEREGRINE uses advanced algorithms integrated wit ch-the-sheff computer hardware configured in sophisticated architectures planning to the desktop.

Better Treatment Strategies Experts have looked at the diagnosis
and treatment planning process to try to explain why current cancer treatments a not more effective.

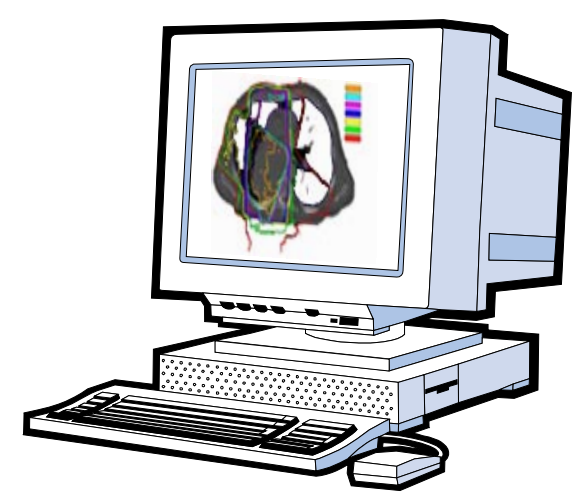

Figure 1. Livermore is using its PEREGRINE radiation Therapy planning process to improve major part of the cancer

CT (compress, which includes (a) dagnosis using high-resolution

When a physician suspects malignancy, acompleized tomography (CT) scan is made of the suspected area to determine the exact position and exte of the tumor. If the cancer has not yet metastasized and is susceptible to radiation, the next step is to develop a plan for radiation treatment (Figure 1). Although T scans provide radiation planners with a three-dimensional (3D) electron-density map of the body, current dose calculation methods model the body as a virtully Inhomogeneities, such as bone and airways, are ignored or highly oversimplified.

Furthermore, interpolated data from dose measurements made in water are used to calculate radiation treatments. These calculations are also based on a variey of simpilications in the way dition is how its energy is deposited.

Some tumors are particularly difficult to treat with radiation because of their proximity to vital organs, the abundance of different tissue types in the area and of different tissue types in the area, and
the differences in their susceptibility to radiation. Cancers of the head and neck

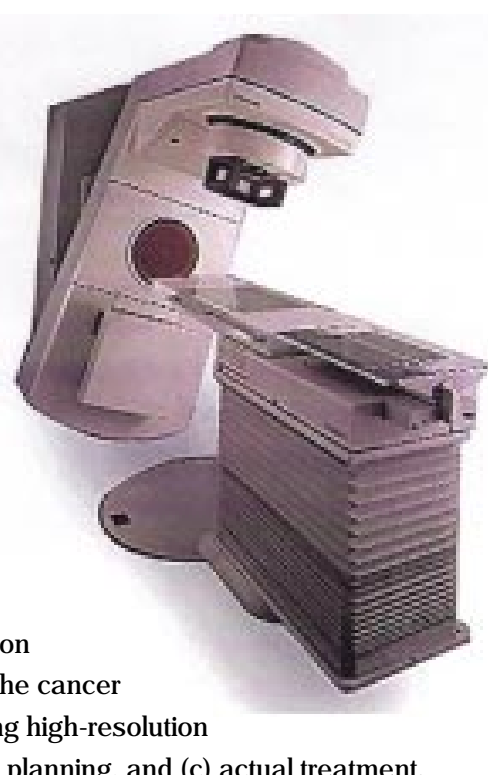

ungs, and reproductive organs are examples. Radiation planners know that too small a dose to the tumor can result in recurrence of the cancer, while too large a dose to healthy tissue can cause complications or even death. Because of calculations, doctors trying to avoid damage to healthy tissue sometimes undertreat cancerous tissue (Figure 2). PEREGRINE is a tool that meets these clinical challenges. It is the only dose calculation system that can be used for all types of radiation therapy, can exactly model the radiation beam delivery system being used for each treatment, anc uses each patient' $\mathrm{S} C \mathrm{~T}$ scan as a basis for the dose calculations. "Most importantly, the PEREGRINE 3D Monte Carlo agorithms, used with Livermore's atomic and nuclear databases, enable the most "These bo calculations," Moses says. "Thpact cencer teet patients who might otherise die."

When PEREGRINE becomes

available for commercial distribution, it will deliver dose calculations economically in today's competitive health-care industry. Because it also can 

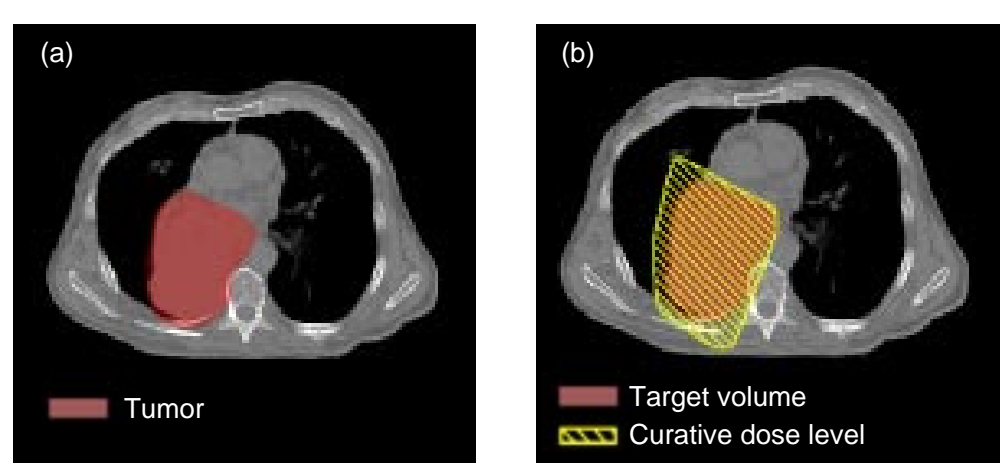

be integrated into existing radiation treatment planning systems throug standard network connections,

PEREGRINE can be installed in every cancer clinic. With PEREGRINE in the hands of radiation oncologists, patient will have access to an unprecedented level of accuracy in treatment planning. Armed with improved knowledge of predicted dose, physicians will be able to develop aggressive new treatment strategies that minimize the risk to

Figure 2. (a) Axial view of a tumor dose calculation available in clinics today indicates complete coverage the tumor with a curative dose. (c) PEREGRIN's Monte Carlo calculaton or the intended dose in (b) would occur near the boundaries of would occur near he boundal of of recurrence.

patients. (See the box below for more

information on radiation therapy.)

Lawrence Livermore has applied two patents for key software and

its first aplication to the US. Fo subm Drug Adminitratio (FDA) Food and year. "Our goal is to make PEREGRIN year. "Ol goul is in cancer treatment centers by late 1998," Sintar says. the left lung. (b) The most accurate

\section{Radiation Therapy}

Radiation has been used to treat cancer for almost 100 years.

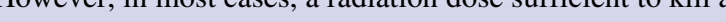
may also injure or damage nearby vital tissues or organs. radiation and applying the right amounts to the right places. Today, tumors usually are treated by beams of particles from particle accelerator, a process known as teletherapy, which is performed with any of four types of radiation. Photon or electron beams are the most frequently used, while therapies using neutrons or heavy charged particles such as protons are largel experimental. Occasionally, treatment may derive from a known as brachytherapy. considered $\mathrm{x}$ rays. They have moderate to long ranges (tens of centimeters), so they can be used for internal tumors. Photon therapy accounts for about $90 \%$ of all radiation treatments in

About 10\% of cancer patients receive electron therapy 列 lying tissues but is not effective for internal tumors.

their energy at one predictable depth or range. By controlling the beam energy, oncologists can control their range. A planner can allor a protor bean to deliver most of its radia. A plose into the per centers in the U.S.

Neutron radiation has the advantage of being more effective han photons for treating But neutron treatment is also very damaging to healthy tissue. Experimental treatment is available at just 20 centers worldwide. New radiation therapies are being developed to treat highly mexpere boron is injected into the body where it is absorbed by cancerous cells. When the body is irradiated by neutrons, the neutrons are are destroyed. Radio-immunotherapy, another approach under study by the research community, uses the chemistry of the body's immune system to target radioactive componds a PEREGRINE is now being

photon, electron, the country. Plans for research with PEREGRINE in the across include collaborations on boron neutron-capture therapy, brachytherapy, and other advanced methods.
PEREGRINE in Action The PEREGRINE dose calculation ncludes two main steps: defining the treatment by describing the radiation source and the patient, and calculating the dose.

Treatment Definition

The treatment-definition generator prepares the data for the specific

treatment. As input, the generato

requires three data sets for each

treatment: the patient transport mesh,

he treatment radiation source, and the

particle interaction database.

Patient Transport Mesh. The

patient s CT scan is composed of

From these, PEREGRINE cra map the pant the density and composition of all the matter in the vicinity of the radiation beam

(Figure 3b). The system creates this map from the CT scan by assigning a materia and density value to each volume eleme (voxel) in the scan. The transport mesh enables PEREGRINE to model details o the patient's body-including irregularities on the body surface, air cavities, and differences in tissue composition-with unprecedented, submillimeter accuracy. The Radiation Source. Accurate dose calculations also depend on reliable information about the characteristics of the radiation beam delivery system.

PEREGRINE is the first dose calculation system to use a complete model for the radiation source of each type of accelerator. The system models the source by dividing the beam delivery system into two parts (Figure 3c). The upper portion of the delivery system is hat do not change from treatment to the do no change fron model has components such as collimators, apertures, blocks, and wedges, which are used to customize the beam for each patient's treatment to ensure coverage of the tumor.
PEREGRINE draws from built-in source libraries to model the upper portion of the system and combines that information with the treatment-specific configuration of the lower portion to produce a model of the radiation being delivered. The source model is the firs description of photon, electron, neutro tescription or photon, electron, neutron, the body.

Particle Interaction Data. In support of its national security mission, Livermore has developed and maintain the world 's most extensive set of atomic and nuclear interaction databases. These particle interactions that enable the allparicle incer

(a) CT-scan stack of patient

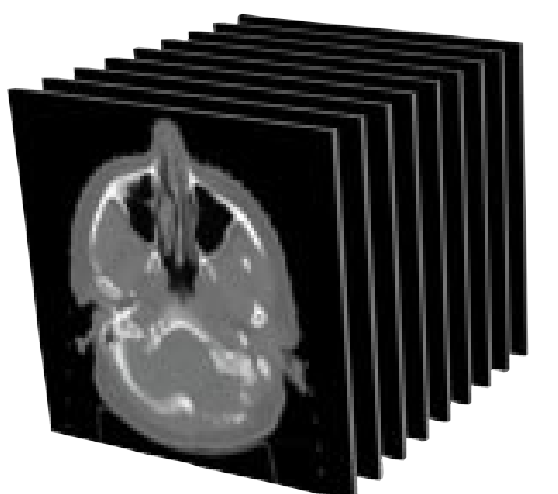

(b) Patient transport mesh

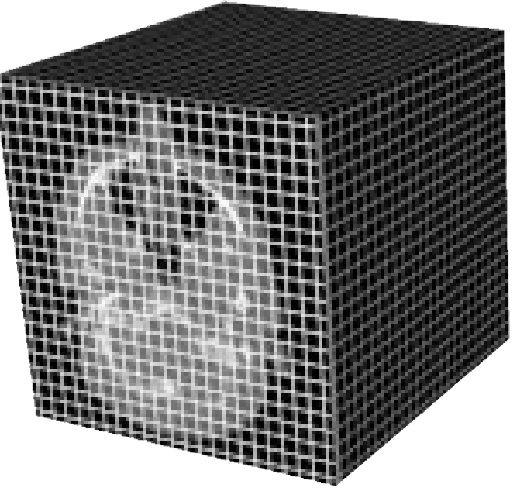

Figure 3. PEREGRINE models both the patient and the radiation source to ensure accurate treatment planning. (a) The CT scan is a stack of image silices less tha 1 centimeter $(\mathrm{cm})$ apart. From these, PEREGRINE creates (b) a 3D transport mesh of the patent to model how radiation (c) PEeract with the materials in the body. (c) PEREGRINE also models the radiation beam source in two pars. the accelerator the components that customize the beam for each treatment

(c) Radiation source model

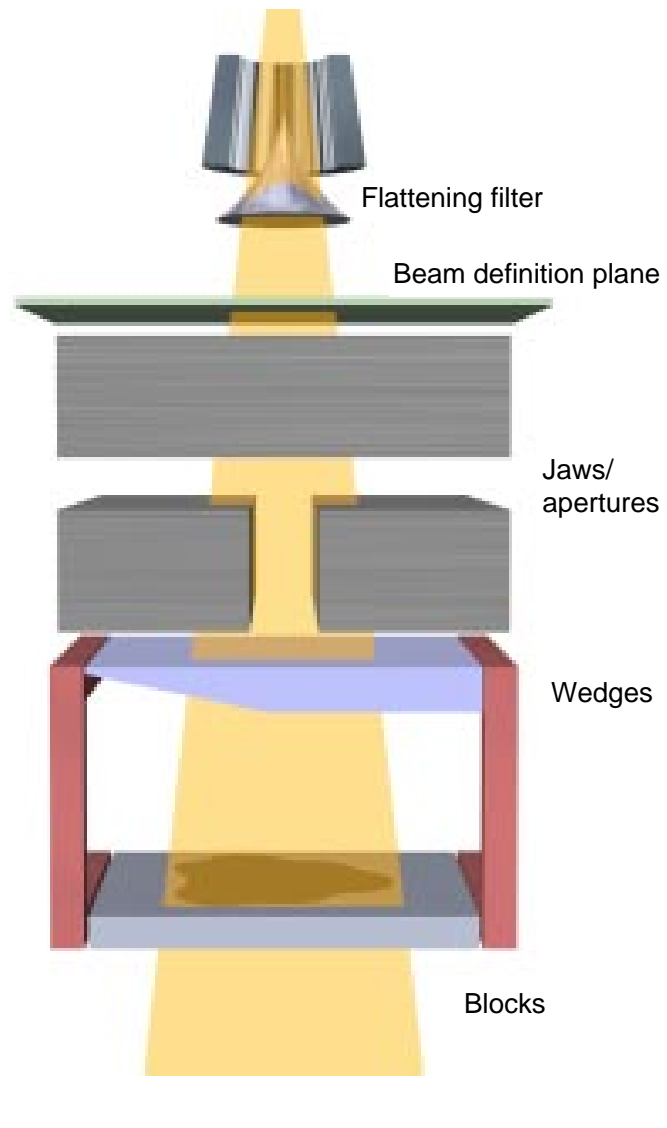



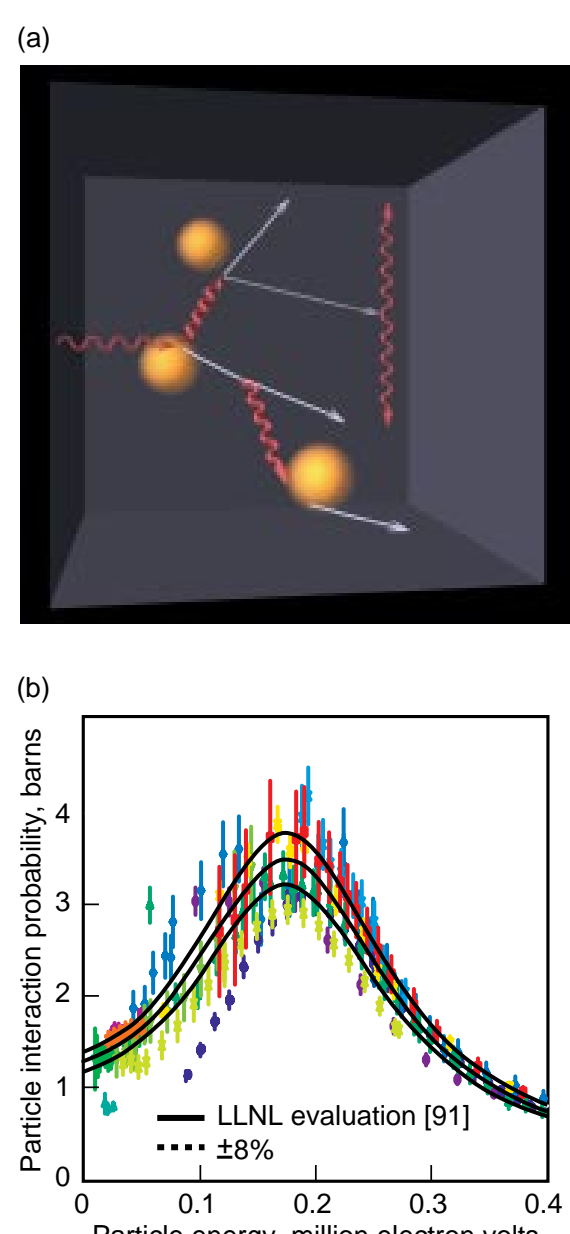

Figure 4. (a) When a particle interacts with the atoms in the body, it creates a shower of secondary (daughter) particles, which in tum move through the body. Lawrence Livermore's all-particle Monte Carlo codes predict these interactons based on information in the Laboratory's comprestive ato reaction from the bestava dabse derived theoretical calculations. (b) The probability of particle interaction depends on the type of particle and the particle's energy. isotope of every element on the periodic table will interact with any radiation particle. To describe the interaction of radiation particles with the muscle, fat, ir, bone, lung, and other tissue in our bodies, PEREGRINE uses interaction

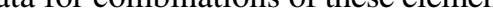
(Figure 4). Fatty tissue, for instance, is $12 \%$ hydrogen, $64 \%$ carbon, $1 \%$ nitrog and $23 \%$ oxygen by weight. Knowing how various radiation particles will behave with these elements enables the system to predict how they will behav

Monte Carlo All-Particle Tracker The tracker selects a particle from the atient sonsport mesh until it ungh the collision. PEREGRINE then cong he interaction database and retrieves information on the incident particle all secondary (daughter) particles resulting from the collision. All the daughter products are tracked as they travel through the transport mesh until they are absorbed in the body or leave the patient. During the simulation, PEREGRINE records the energy deposited at each interaction, building up a map of absorbed dose in the patient transport mesh. By repeating the process for millions of the trillions of particles a patient receives in a treatment, the Monte Carlo algorithm produces a statistically realistic picture of an entire irradiation. Figure 5 illustrates the dose buildup in a radiation treatment. The more particles that are tracked, the more accurate is the simulation of the treatment and the bet is the information for the doctor. But lies the challenge-attaining both accuracy and speed.

Supercomputer to Desktop The historical problem with Monte Carlo has been that the radiation treatment planning community cannot afford a urnaround time of more than an hour to meet its caseload. Previously, even on \$20-million Cray-1 supercomputer, a single dose calculation took weeks to complete. So Monte Carlo calculations emained in the weapons, reactor, and high-energy-physics research communities where the turnaround time for calculation could stretch over months.

Livermore computer experts have combined state-of-the-art computation techniques and advanced computer architecture to bring Monte Carlo
treatment planning to the hospital treatment planning to the hospital Taking advantage of recent strides in microcomputer technology, the

PEREGRINE dose calculation engine colf developed for file- and Internet-server applications. PEREGRINE can be integrated into any treatment planning system via conventional network connections. Adding it to an existing system will be as easy as adding a file

The system design uses multiple processors interconnected by an interna high-speed network. The physics software distributes the calculations for a proble so that the dose is calculated by many microprocessors in parallel. The number of microprocessors can be determined by the user. For example, a big-city clinic that plans many radiation treatments each day would require a larger number of microprocessors to enable the fastest possible turnaround time. A suburban rural clinic hat does fewer radiation expensive system. The system dess supports hardware upgrast to calcultion future technological changes. Now, a PEREGRINE calculation takes about
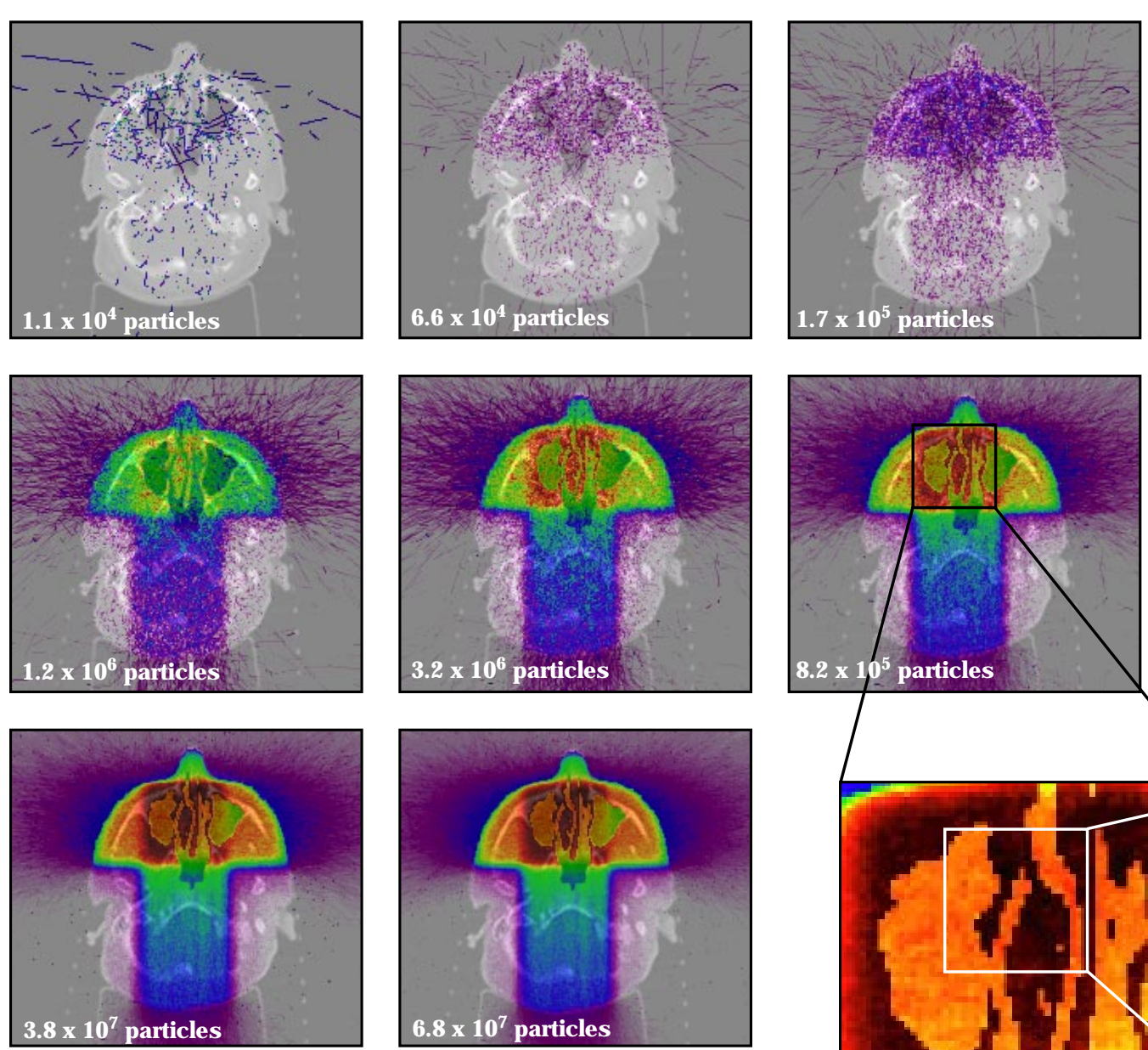

continue and as microprocessor chips improve, the system will be even faster.

Clinical Verification

Almost since work began on

PEREGRINE, the Livermore project

team has worked closely with an advisor board of internationally respected medica physicists and physicians in radiation on p. 10.) Dubbed the MEDPAC (Medical Physics Advisory Committee), incorpon this new technology is sics and tha this new techno
clinical setting.

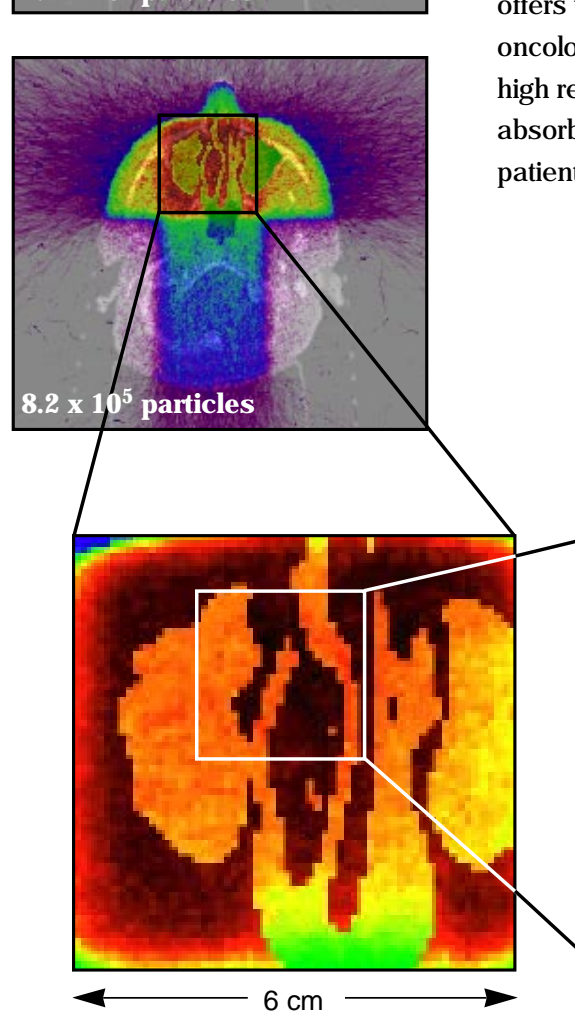

The project team is particularly interested in validating the accuracy of PEREGRINE dose calculations again clinical measurements for photon bean (or x-ray) therapy, the most frequently used form of radiation therapy (Figure 6). The Universty or California, San 650 dose (UCS), has provided over variety of miand and simulate conditions in the patient. UCSF and the Medical College of Virginia have and the Medical College of Virginia have calculation comparisons for patients wih tumors in the head and neck, spine, lung, and larynx. Livermore has also begun a collaboration with the Radiation Therapy Oncology Group, a team sponsored by

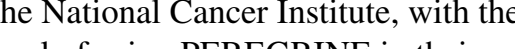
goal of using PEREGRINE in their new 3 lung cancer treatment protocol

Throush the afferts pations. Thingh hese effrts, Livermore is radiation source characterizations, validate the PEREGRINE dose calculations against clinical measurements, and evaluate the 
MEDPAC Advisory Committee

Livermore has depended on the medical community for input in developing PEREGRINE. In addition to Lawrence Livermore, hospitals and organizations represented on the MEDPAC include:

- University of Wisconsin Medical School

- Massachusetts General Hospital Harvard Medical School - M.D. Anderson Cancer Center - Gershenson Radiation Hospital, Detroit

- Loma Linda University Medical

Center

- Memorial Sloan Kettering

Cancer Center

- Washington University

San Francisco

Louvain, Brussels, Belgium

- Los Alamos National Laboratory

Figure 6. Comparison of PEREGRINE calculations

and clinical measuremen

of radiation dose in water

from the University of

Califomia, San Francisco.

Show PEREGRINE's

unparalleled accuracy in

predicting the deliver

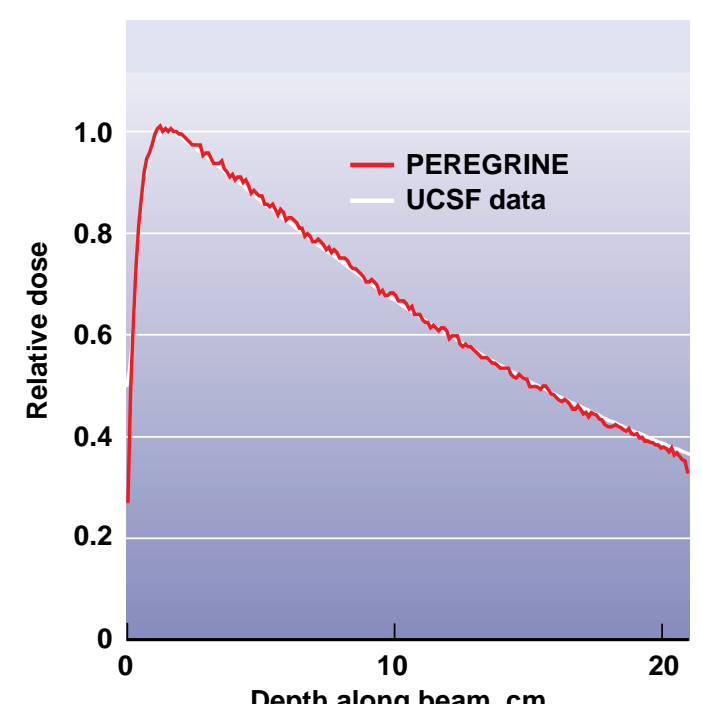

Depth along beam, $\mathrm{cm}$ he patient's outcome. Ultimately, the system should facilitate more accurate standardized clinical trials and more thiliable implementation of those resuls

\section{A Look Ahead}

Livermore is now working with the radiation treatment-planning commun assure that PEREGRINE integrates easily into existing treatment-planning systems as a simple upgrade. Lawrence tivermore plans to license PEREGRIN will be went-planing vendors so that In we nel avillable.

In the near ante, he project tea plans to nake PEREGRINE fally pric brachytherapy. (See box on $\mathrm{p}$.

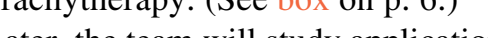
for heavy-particle (neutron and proton) therapies, which are used for cancers and around the salivary glands, spinal cord, and eye

The team is also pursuing collaborations in the application of the system to cancers of the breast and impact of accurate dose calculations on

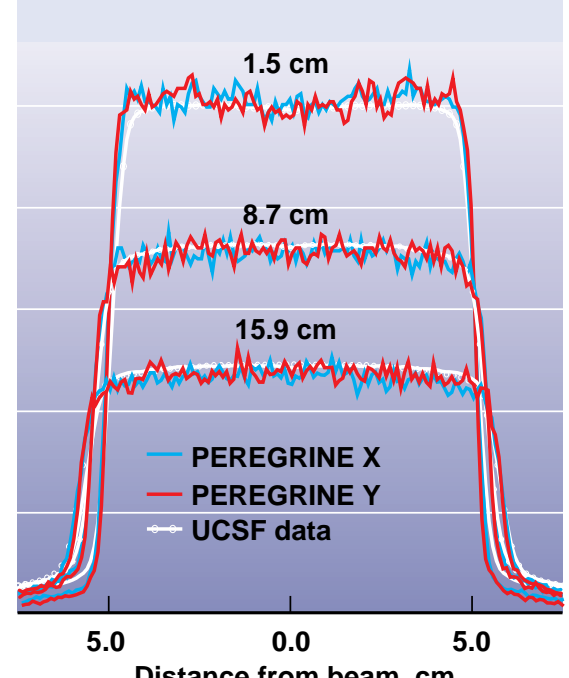
fully model the dose buildup near th surface of the breast, which is very important because of the area's sensitivity to radiation burns. Accurate dose calculations for prostate cancer are critically important because of the

As PEREGRINE becomes more sophisticated, it may change the way Today, a discios are planned. The CT scus to degist studies a adiation should and hound not must be to destroy the tumor. The medical physicist and dosimetrist the recommend a plan to deliver the radiation (numbers of beams, angles, etc.) prescribed by the oncologist. The PEREGRINE project team plans to bring "inverse planning" to this process, whereby treatment goals are established by the oncologist and input into PEREGRINE, which the determines how best to deliver the radiation to the patient.

D.0 $\quad 0.0 \quad 5.0$ prostate. PEREGRINE is the only dose calculation algorithm today that can
"PEREGRINE may soon help to "Its high accuracy, speed, and affordability add up to the likelihood of widespread use at research hospitals and small clinics, which will bring superior radiation dose calculations and better treatment to -Katie Walter

Key Words: cancer treatment, Monte Carlo physics, nuclear databases, radiation dose
calculations, radiation therapy, tumors.

For further information contact Edward Moses (510) 423-9624 (moses1@IInl.gov) Christine Siantar (510) 422-4619 (hiting phys.IInl.gov/peregrine/).
About the Team

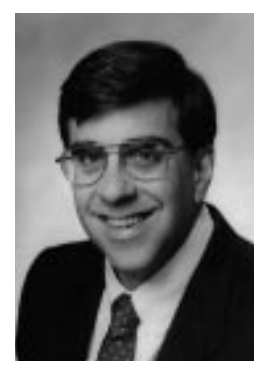

DOSES, PERECRINE program leader since 1994, ceived a Ph.D. (1977) in electrical engineering from Cornell University, where he specialized in quantum electronics. erlier Lawrence Livermore experience includes program

manager of the AVLIS (Atomic Vapor Laser Isotope Separation) Program from 1986 to 1990

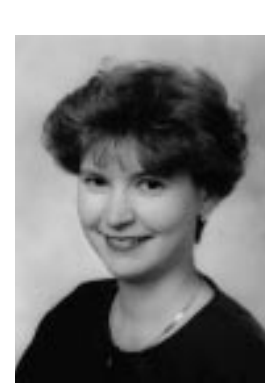

HRISTINE SIANTAR, principal investigator of the

PEREGRINE program, received her Ph.D. (1991) in medical

physics from the University of Wisconsin. Prior to joining

Lawrence Livermore in 1994, she gained experience in cance treatment planning at the Medical College of Wisconsin. Her

culations for PEREGRINE.

PEREGRINE: Improving Radiation Treatment for Cancer

The Lawrence Livermore National Laboratory has developed a radiation dose calculation system that will provide the most accurate and highest resolution treatment planning capability available. PEREGRINE is designed to be fast and affordable and will run on low-cost computer hardware in a hospital network environment. The availability of such accurate dose calculations will improve the effectiveness of radiation therapy by providing quality radiation treatment planning for patients in every clinical environment and facilitating accurate clinical trials. PEREGRINE will provide accurate estimates of required doses for tumor control and normal tissue tolerance and will advance the field of radiation oncology. It can methods of radiation therapy and could help save thousands of live each year. 


\section{The Unitized \\ Regenerative Fuel Cell}

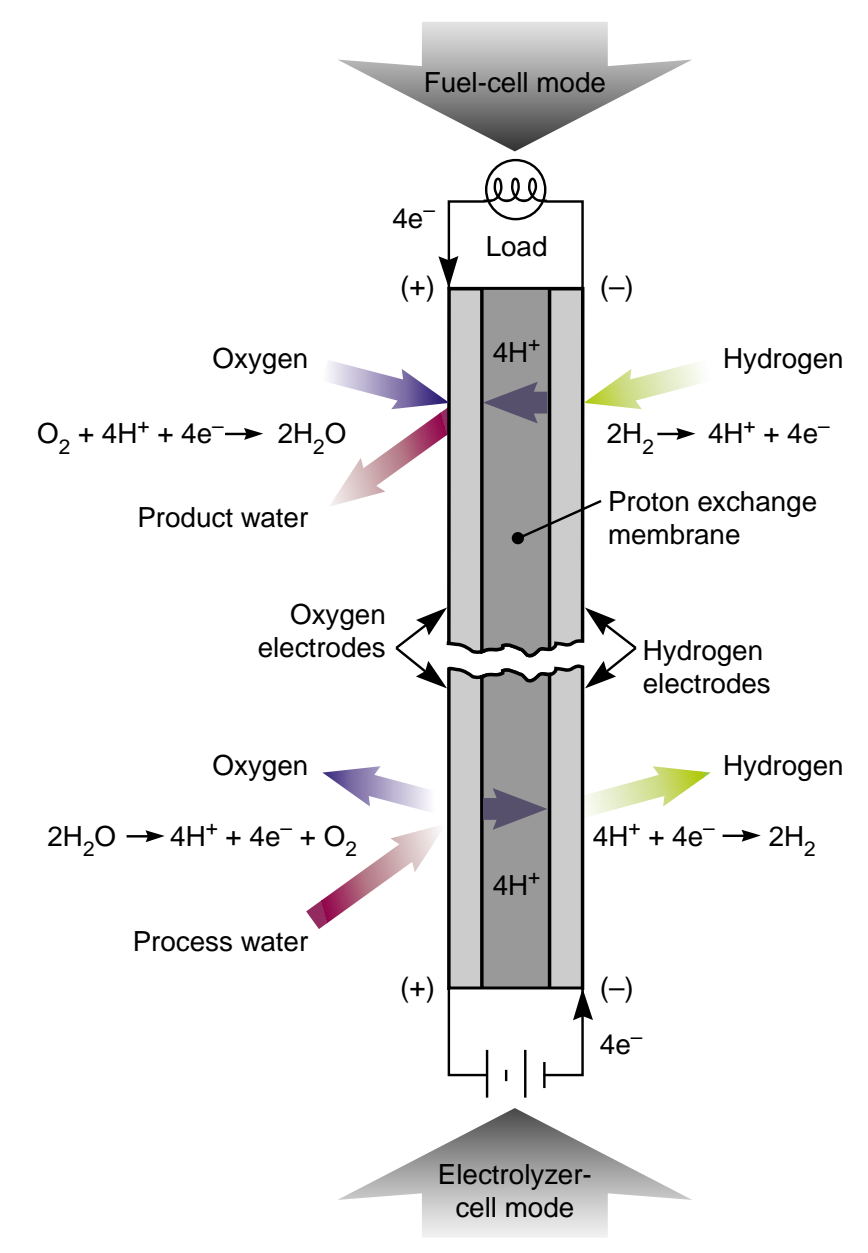

Figure 1. The electrochemistry of a unitized regenerative fuel cell. In the fuel-cell mode, a proton-exchange membrane combines oxygen and hydrogen to create electricity and water. When the cell reverses to create oxygen and hydrogen.
CIENTISTS are searching for cleaner ways to power vehicles and to make better use of domestic energy resources. The fuel cell, an electrochemical device that converts the chemical energy of a fuel directly to usable energy without combustion, is one of the most promising of these new technologies. Running on hydrogen fuel and oxygen from the air, a 50-kilowatt fuel cell can power a lightweight car without creating any undesirable tailpipe emissions.

If the fuel cell is designed to operate also in reverse as an electrolyzer, hien electricity can be used to convert the wate back into hydrogen and oxygen. (See Figure 1.) This dualfunction system is known as a reversible or unitized regenerative fuel cell (URFC). Lighter than a separate electrolyzer and generator, a URFC is an excell where weight is a concern.

Weigh scientists at

faw for an unmanned, solar-powered aircraft to be used for highaltitude surveillance, communications, and atmospheric sen

as part of the Strategic Defense Initiative. Called Pathfinder, the aircraft set an altitude record for solar-powered flight in 1995 , flying to 15,400 meters (50,500 feet) and remaining aloft for about 11 hours. Pathfinder's successor, Helios, will remain aloft for many days and nights. For that aircraft, storage devices were studied that would provide the most energy at the lowest weight, i.e., the highest energy density. The team looked at flywheels, supercapacitors, various chemical batteries, and hydrogenoxygen regenerative fuel cells. The regenerative fuel cell, coupled with lightweight hydrogen storage, had by far the highest energy density -about 450 watt-hours per kilogramten times that of lead-acid batteries and more than twice that forecast for any chemical batteries.

The Prototype

Fuel cells have been used since the 1960s when they supplied on-board power for the Gemini and Apollo spacecraft. Today, fuel cells are being used for Space Shuttle on-board power, power plants, and a variety of experimental vehicles. harly experience did not uncover the use early experionce dittle of Livermore research indicate otherwise, based on mos thorough systems en incering and improved membrone technology.
Challenged by a lack of information on the technology, just how to make the combination of technologies work. Mitlitsky continued in 1994 with a little funding from NASA for development of Helios and from the Department of Energy for leveling peak and intermittent power usage with sources such as solar cells or wind turbines. (See Figure 2.)
The 50-watt prototype that Mitlitsky's team developed is a single proton-exchange membrane cell (a polymer that passes protons) modified to operate reversibly as a URFC. It uses bifunctional electrodes (oxidation and reduction electrodes that reverse roles when switching from charge to discharge, as with a rechargeable battery) and cathode-feed electrolysis (water is fed from the hydrogen side of the cell). By November 1996, the prototype

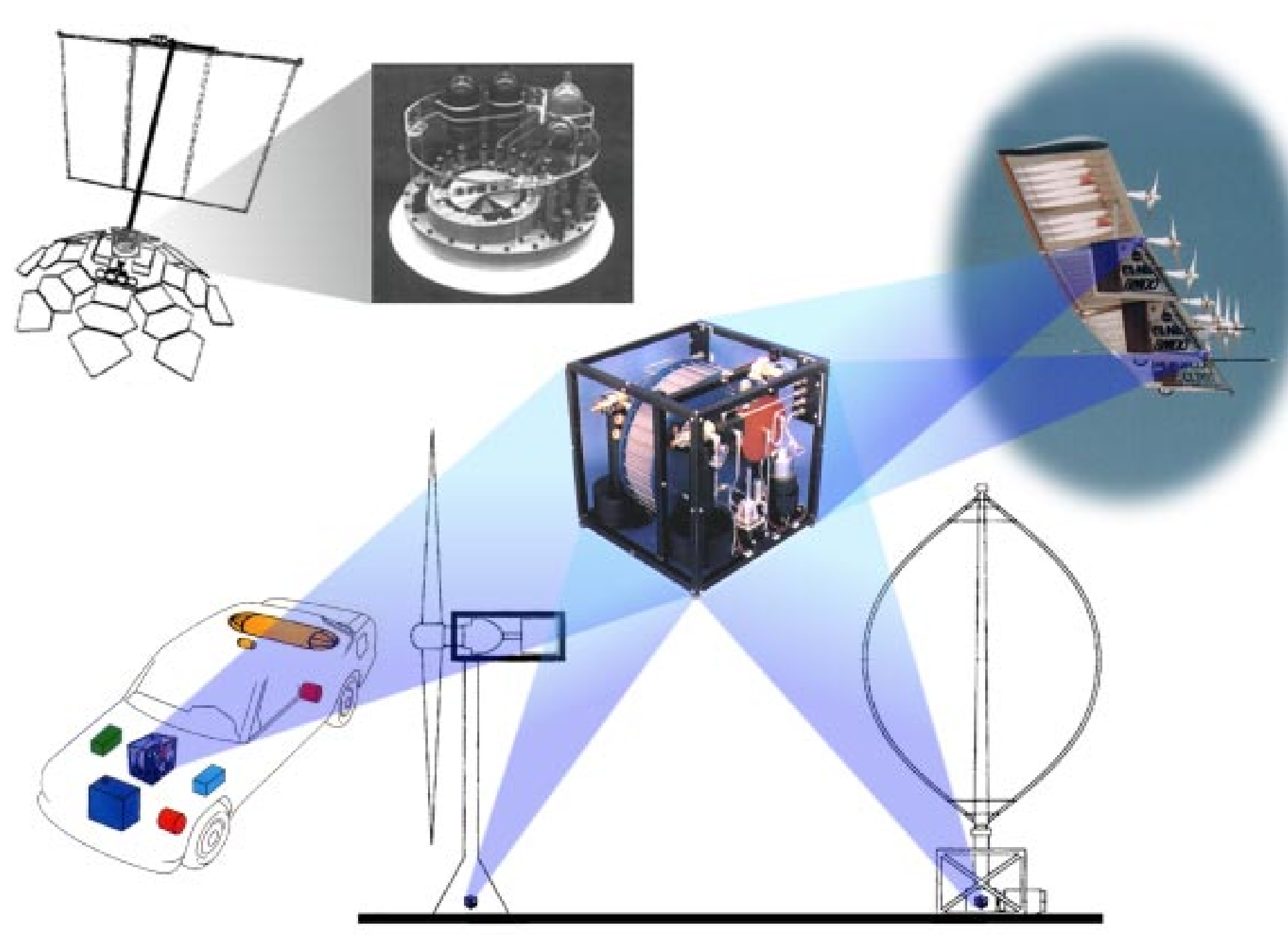

Figure 2 Unitized regenerative fuel cells will someday find a multitude of applications. URFCs are ideal for cars, solar-powered aircraft, energy torage. 
had operated for 1,700 ten-minute charge-discharge cycles, and degradation was less than a few percent at the highest current densities.

Testing will continue in a variety of forms. Larger, more powerful prototypes will be created by increasing the size of the membrane and by stacking multiple fuel cells. For use on Helios, a prototype will likely provide 2 to 5 kilowatts running on a 24-hour charge-discharge cycle. As funding become available, prototypes may also be tested for other uses. A lu rover, for example, would require cycles of about 29 days.

URFC-Powered Electrical Vehicles

In a 1994 study for automotive applications, Livermore and the Hamilton Standard Division of United Technologie priced URFCs. They found hat compared with batterypowered systems, the URFC is lighter and provides a driving a a vehicle, they fo f a vehicle, hay for In a resident powered car can also recoup hydrogen and oxygen when driver brakes or descends a hill. This regenerative braking feature increases the vehicle's range by about $10 \%$ bnd could replenish a low-pressure (1.4-megapascal or 200-psi) oxygen tank about the size of a football.

In the fuel-cell (discharge) mode, stored hydrogen is combined with air to generate electrical power. The URFC can also be supercharged by operating from an oxygen tank instead of atmospheric oxygen to accommodate peak power demands such as entering a freeway. Supercharging allows the driver to accelerate the vehicle at a rate comparable to that of a vehicle powered by an internal-combustion engine. The URFC in an automobile must produce ten times the power of the Helios prototype, or about 50 kilowatts. A car idling requires just a few kilowatts, highway cruising abou 10 kilowatts, and hill climbing about 40 kilowatts. But acceleration onto a highway or passing another vehicle URFC's URFC's supercharging feature supplies the additional power. A URFC-powered car must be able to store hydrogen fued A bard, but existing tank systems are relatively heavy, for a New Generation of Vehicles, a government-indushyp consortium dedicated to developing high-mileage cars, the Ford Corporation provided funding to LLNL, EDO Corporation, and Aero Tec Laboraties for development of a lightweight hydrogen storage tank (a pressure vessel). The team combined a carbon fiber tank with a laminated, metalized, polymeric bladder (much like the ones that hold beverages sold in boxes) to produce a hydrogen pressure vessel that is lighter and less expensive than conventional hydrogen tanks. Equally importan its performance factor-a function of burst pressure, internal volume, and tank weight-is about 30\% higher than that of consarable carbon-fiber hydrogen storage tanks. In tests where cars with pressurized carbon-fiber storage tanks were dropped from heights or crashed at high speeds, the cars generally were demolished while the tanks still held all of their pressure-an effective indicator of tank safety.

Unlike other hydrogen-fueled vehicles whose refueling needs depend entirely on commercial suppliers, the URFC-powered vehicle carries most of its hydrogen infrastructure on board But even a highly efficient URFC-powered vehicle needs periodic refuling. Until a netwro of commercial hydrogen hoppliers is deve. Uned, an overnight recharge of a small car at (150-mile) dring ren released electrical vehicles. With the infrastructure in place, a 5-minute fill up of a 35-megapascal (5,000-psi) hydrogen tank would give a 580 -kilometer (360-mile) range.

Commercial development of unitized regenerative fuel cells or use in automobiles is perhaps 5 to 10 years away. With their long life, low maintenance requirements, and good performance, URFCs hold the promise of someday supplying clean, quiet, efficient energy for many uses.

-Katie Walter

Key Words: electric cars, fuel cell, Helios, hydrogen, Partnership for New Generation of Vehicles, zero-emission vehicles.

References

Pretlitsky, B. Myers, and A. H. Weisberg, Lightweight Pressure Vessels and Unitized Regenerative Fuel Cells, LLNL,
Livermore, California, UCRL-JC-125220 (November 1966). Presented at the 1996 Fuel Cell Seminar, San Diego, California, November 17-20, 199

tsky, N. J. Colella, and B. Myers, Unitized Regenerative Fuel Cells for Solar Rechargeable Aircraft and Zero Emission
Vehicles, LLNL, Livermore, California, UCRL-JC-117130 (September 1994). Presented at the 1994 Fuel Cell Seminar,

Orlando, Florida, November 28-December 1, 1994.
3. "Getting along without Gasoline- The Move to Hydrogen Fuel,"

"Getting along without Gasoline-The Move to Hydrogen Fuence \& Technology Review, UCRL-52000-96-3 (March Science \& Technologe
$1996)$, pp. 28-31.

For further information contact Fed Mitlitsky (510) 423-4852 (fm@IInl.gov).

\section{Better Flash Radiography Using the FXR}

MAGINE a very powerful $x$-ray machine, several billion times more powerful than the one your dentist aims at you jaw. X rays can penetrate more than a foot of steel and record the motion of materials moving at ultrahigh speeds, making i an excellent tool for peering into the interior of a nuclear weapon's imploding primary stage.

. of a nuclear weapon from ignition to the beginning of the nuclea chain reaction. These experis The resulting explosive

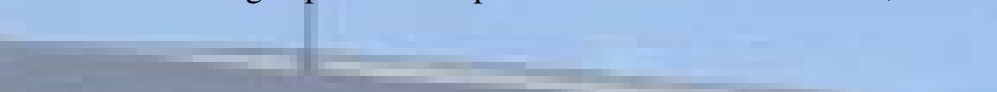

This photograph of a typical experiment using the Flash $X$ Ray was taken almost 20 milliseconds after detonaton, long after the $\mathrm{FXR}$ had $\mathrm{nish}$

its data collection. The $\mathrm{FXR}$ is housed in the
building to the left of the fring table. makes it denser, and even melts it. This process replicates the effects in the core of a nuclear device. High-speed radiographic images of the implosion process are taken with the powerful x-ray machine known as the Flash X Ray, or FXR, which was developed by scientists at Lawrence Livermore Nationa Daboratory in the early $1980 s^{\prime}$

Data from the FXR's x-ray images are used to verify and In thalize Livermore's computer models of device implosions. no certify the safety and relibility of nuclear weapons a citical part of the Laboratory's role in the stewardship of our nation, nuclear stockpile. 
To improve capabilities for science-based stockpile stewardship, Lawrence Livermore has been upgrading many diagnostic facilities at Site 300, the Laboratory's experiment test site. The FXR was already the most sophisticated hydrodynamic flash radiography system in the world. response to the need for data supporting ever more exact computer modeling codes, it has been made more powerf and capable of producing sharper, more useful radiographs.

The FXR in Action

The FXR is an induction linear accelerator specifically designed for diagnosing hydrodynamic tests and radiographing the interior of an imploding high-explosive device. Its $\mathrm{x}$ rays penetrate and are scattered or absorbed by the materials in the device, depending upon the density an absorption cross section of the various interior parts. The form the image on photographic emulsions or on the recording surface in a gamma-ray camera.

An injector introduces an electron beam into the FXR An enters a drift section that directs it tow ard a 1 - hillime beam strip of tantalum, called a target. As the high-energy electron pass through the target, the electric field created by the stationary charged particles of the heavy tantalum nuclei causes the electrons to decelerate and radiate some of their energy in the form of $\mathrm{x}$ rays. The product of this slowing process is called bremsstrahlung (braking) radiation.
The x-ray photons travel toward the exploding device, where most are absorbed. The photons that make it to the camera are the image dat

A Better Radiographic Process

The upgrades to the FXR centered on improving the quality of the beam and adding a new gamma-ray camera system tha

is 70 times more sensitive than radiographic film. In this camera, designed by Livermore scientists, the beam hits an array of bismuth-germanate crystals with which the $\mathrm{x}$ rays interact to generate visible light. This light is recorded on photographic film

The first task in increasing FXR beam quality was to improve the magnetic field that transports the electron beam through the accelerator. New focus solenoids and printed-circuit magne steering colls were ins slled in each of the accelerator and pelling 10 to 20 .

The next task was to doble the injector beam voltage foom

to double the injector beam voltage from 1.2 megavolts to 2.5 megavolts. At the same time, the injector electron beam current was increased from

2.2 kiloamperes to 3 kiloamperes. The number of

cells in the injector was increased from six to

ten, and the electron diode and the injector

magnetic transport solenoids were redesigned.

With the completion of these upgrades, the

FXR is producing a higher overall $\mathrm{x}$-ray dose and a smaller spot size. Today, the central portion on the $\mathrm{x}$-ray spot is twice as intense compared with pre-upgrade levels. Because tuning the FXR is an ongoing process, improvements in performance are expected to continue.

Prior to the addition of the gamma-ray camera, the size of the beam where it hits the tantalum target was a major concern a smaller "spot size" increases the sharpness and clarity of the radiographs. Achieving a smaller effective spot size was accomplished by passing the $\mathrm{x}$ rays through a small hole in a thick plate near the target, a process known as collimation. Bu ecause $\mathrm{x}$ rays emitted outside the collimation diameter are lost to the radiographic process, collimating the beam mean that thicker materials could not be studied.

Today, however, the increased sensitivity of the gamma-ray camera and the increased current density of the central portion of the electron beam combine to more than compensate for the losses due to collimation. The gamma-ray camera can produce available dose. The cages than before even with a lower newly increased $\mathrm{x}$-ray dose at the target means that collimation can be used for experiments involving even higher density materials. Preliminary results indicate that the FXR upgrade-in conjunction with the gamma-ray camera-have significantly improved the radiographic capability at Livermore. In the near future, the Laboratory will be adding a double-pulse feature to the FXR to provide two radiographs of a single explosionmplosion separated by 1 to 5 microseconds. Researchers can use his information to follow the time evolution of an implosion and learn more about how an implosion progresses. Restoring singlehot, full-energy operation will require simply setting the pulse interval to zero. Livermore scientists are also developing a twoframe gamma-ray camera to capture the fast successive images of double-pulsed FXR radiography and record them on a charged.

Key Words: flash x radiography (FXR), gamma-ray camera,

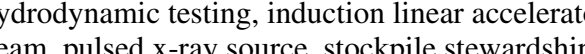

For more information contact Ray Scarpett (510) 422-8502 (scarpetti1@IInl.gov).

The Flash X-Ray

beam area is on the

same level as the

firing table outside

the building. The

electronics corrido

optics room, and

control room are

underground, one

level below the

beam area and

offset from the

accelerator as

shown in this

schematic. Several

cells can be seen

in the photograph

to the right
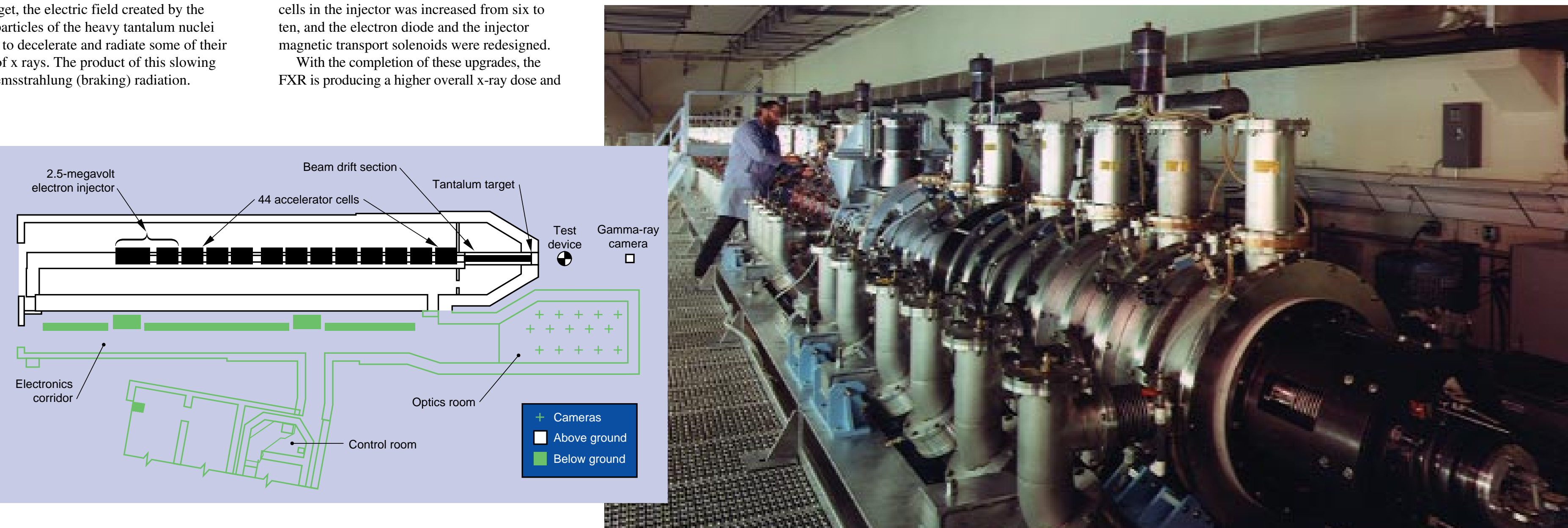


\section{Preserving Nuclear Weapons Information}

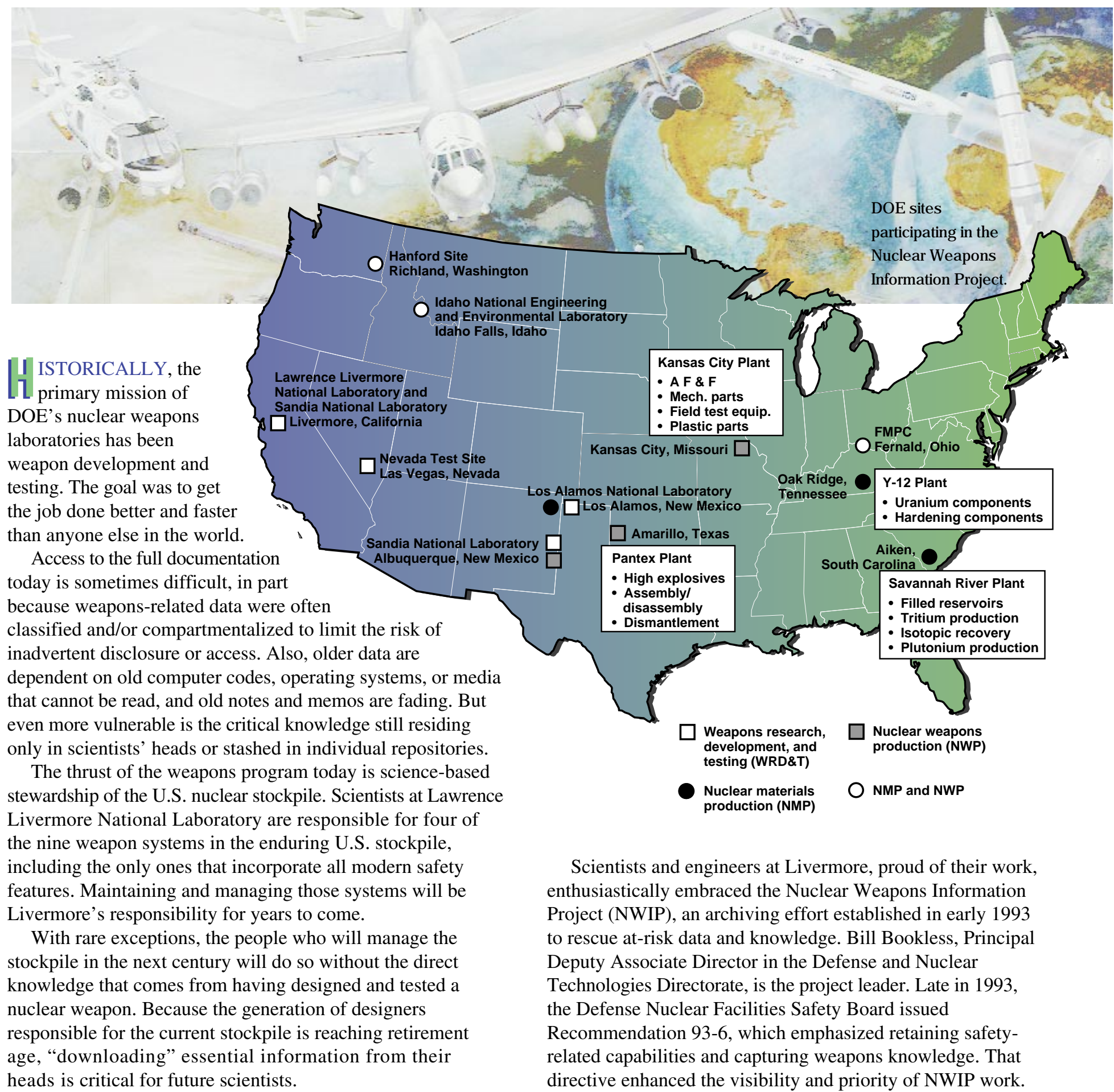

The Nuclear Weapons Information Project will preserve Livermore's portion of the Department of Energy's Stockpile Stewardship and Management Program. It will also preserve data for training future scientists, engineers, and technicians and will provide immediate critical information for emergency

response to nuclear weapon incidents.

The information archived in NWIP will support proliferation analyses to deter the spread of nuclear weapons to other countries and to terrorist organizations. And the database will provide the fundamental information necessary to resume weapons design, development, testing, and production if required by changes volatile world situation

Because scientists at Livermore depend on access to nformation at all DOE nuclear weapon facilities, in 1994 Livermore also took a leading role in implementing an informatio Len participants from the DOE sites shown in the figure, the Department of Defense's Defense Special Weapons Agency, ind the United Kingdom's Atomic Weapons Establishment.

\section{The Task at Hand}

When work began on the DOE project, the most critical need were learning what information existed and how to get approprias access to it. Some DOE sites have as many as 300 different databases or catalogs of relevant data. And some data shelved in unmarked boxes have never been catalogued. Consequently, the initial focus of the group was on "metadata," which are data abo data-typically bibliographic data-and on standardization effor

Terminology has changed over time, and various organizations. across the DOE complex use different terms for the same thing. Local glossaries have been developed and are being shared and integrated, and a categorization system is being developed to define common subject areas. Livermore leads the working group that is developing metadata standards and has led the pilot implementation of searches in and across multiple catalogs. Capturing documents and data is actually the easy part of the project. Capturing the knowledge that is in people's heads and that cuts across program boundaries is more difficult. Videotapes are being made of panel discussions, tours, lectures, and operations to save undocumented anc

Livermore has already adopted the NWIG standards an Leces by implementing commercil "browser"

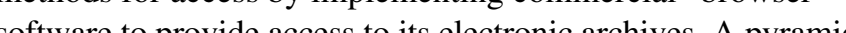
need-to-know model is also being implemented, such that individuals authorized at the top of the pyramid may have access to nearly everything while those authorized at other levels have access only to information in a particular domain or perhaps about specific weapon systems. By enhancing its classified network infrastructure, Livermore can balance the increased access to information against the increased threat of compromise. Translating archived files into such standard formats as HyperText Markup Language (HTML) and Portable Document Format (PDF) minimizes the number of platform-sensitive formats that must be translated indefinitely as the technology changes. Settling on a few standard formats also allows the search engine to index every word of every document for retrieval. Links can then be made to the actual archived online documents, or for catalog searches, the search engine
can indicate where the documents can be found.

Cutting-Edge Technologies

Several advanced technologies are being applied to the uclear Weapons Information Project at Livermore. An example is the online video search and retrieval system, which will provide authorized users of the archives access to videotape information through a search of the automatically generated transcripts. A search will yield both words in the transcript and matching video images.

The access control mechanisms work together with stateof-the-art identification and encryption technology to ensure authorization, authentication, and secure delivery of information on distributed classified networks. Administrators in weaponsrelated divisions at Livermore are also making use of this new commercial technology to better protect sensitive unclassified information. Livermore is leading the effort across the DOE complex to establish and implement access control policies and procedures.

Information Is a National Asset

Downloading the knowledge from scientists' heads and archiving those stashed personal files - plus organizing and categorizing more accessible data-are essential tasks. The project team is establishing the archives so that this accumulated information, an important national asset, is preserved for the long term and readily accessible whenever needed. The succes Program depends on these new archives.

Key Words: archives, Nuclear Weapons Information Project, Stockpile Stewardship and Management Program.

For further information contact Bill Bookless (510) 424-3953 (wbookless@lInl.gov). 
Patents

\section{Patentissued to}

Patent title, number, and date of issue

Kenneth W. Neufeld

\section{Electromechanical Cryocooler}

U.S. Patent $5,582,013$
December 10, 1996

Alan T. Teruya
J ohn W. Elmer

Tomographic Determination of the Power Distribution in Electron Beam

U.S. Patent $5,583,427$

Laura N. Mascio Automated Analysis for
Microcalcifications in High Resolutio Digital Mammograms

U.S. Patent $5,586,160$

M. Allen Northrup $\begin{array}{ll}\text { M. Allen Northrup } & \text { Silicon-Based Sleeve Devices for } \\ \text { Raymond P. Mariella, Jr. Chemical Reactions } & \end{array}$ Anthony V. Carran U.S. Patent 5,589,136
December 31, 1996

Thomas E. MCEwan Short Range Radio Locator System U.S. Patent $5,589,838$

J ohn S. Taylor Precision Non-Contact Polishing Tool U.S. Patent 5,591,068
J anuary 7, 1997

\section{Summary of disclosure}

A device for cooling instruments, such as radiation detectors, while minimizing vibrations. It contains a compressor with a linear motor and
piston and measuring device to measure the direction and force of the compressor's vibrations. It also has a controller, mechanically coupled to the compressor, that takes signals generated by the measuring device and responds with a counterforce, which reduces the vibrations. The input of acceleration of the cooler while it performs its themodynamic function.

A technique for determining the power distribution of an electron beam using electron-beam profile data acquired from a Faraday cup to create an mage of the current density in high- and low-power beams. A refractory The beam acquires the data by sweeping in a circular pattem so that its path crosses each slit in a perpendicular manner. A computer generates the signals to actuate the sweep, acquires data, and does the

A computer-aided method and apparatus for diagnosing breast cancer. A computer algorithm using gray-scale morphology is implemented to automatically detect, analyze, and flag microcalcifications in digitized film each potential microcalcification detected in these images, a number of features are computed to distinguish between the different kinds of objects detected. A selective erosion or enhancement filter helps weed out false alarms. The algorithm determines which portions of a mammogram to store space.

A chemical reaction chamber made of doped polysilicon for heating and bulk silicon for convective cooling combined in a critical ratio so that the the reaction mixture, thereby avoiding any potential material incompatibilities. The chamber can be used in chemical reaction systems for synthesis or processing of organc, hingrganc, or bickemical reactons. ner DNA reactions.

A wireless transmitter that outputs periodic bursts of radar carrier signals. A receiver system determines the position of the transmitter by the relative arrival of the radar burst at several component receivers specially located. One receiver provides a synchronizing gating pulse to iself; the other pulse is slighty offset from the rate of the radar bursts, so that each sa collects one finely detailed piece of information about the time of flight of the radar pulse to each receiver for each pulse period.

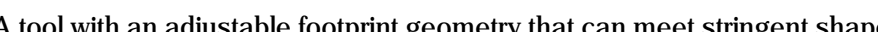
and finish tolerances on precision surfaces during fabrication. Two orthogonal slurry flow geometries provide flexibility in altering the shape of the removal footprint. The tool is applicable for $x$-ray optical surfaces, $x$-ray

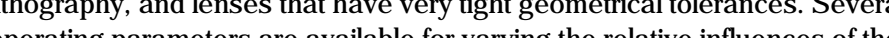
operating parame
mechanism.
Patents (continued)

Patent issued to

Michael A. Do

Patent title, number, and date of issue

System and Method for

multaneously Collecting Serial

Numerous Identity Tags

U.S. Patent5,591,95

J anuary 7. 1997

$\begin{array}{ll}\text { Edward J. Kansa } & \text { Nontoxic Chemical Process for In } \\ \text { Ananda M. Wijesinghe } & \text { Situ Permeability Enhancement an }\end{array}$ Accelerated Decontamination of

U.S. Patent 5,593,248 J anuary 14, 1997

U.S. Patent $5,593,24$
J anuary 14,1997

$\begin{array}{ll}\text { Paul D. Sargis } & \text { Subcarrier Multiplexing with } \\ \text { Ronald E. Haigh } & \text { Dispersion Reduction and Direct } \\ \text { Kent G. McCammon } & \text { Detection } \\ & \text { U.S. Patent 5,596,436 } \\ & \text { January 21, 1997 }\end{array}$

Thomas J . Kar Passive Infrared Bullet Detection
and Tracking U.S. Patent $5,596,509$
anuary 21,1997

George D. Craig Bemhard Rup

System and Method for Forming Synthetic Protein Crystals to
Determine the Conformational Structure by Crystallography U.S. Patent 5,597,457
J anuary 28, 1997
Smmary of disclosure

A system that simultaneously collects and reports serial number Each tag's multididiats serial number is stored in nonvolatile RAM. A rags, transmits an ASCII-coded "D" character on a 900-MHz carrier and a 1.6$\mathrm{GHz}$ power illumination field. A 1-MHz tone is modulated on the 1.6-GHz camier as a timing clock for a microprocessor in each of the identity tags.

A remediation method for the removal of certain liquid and solid phase contaminants from low-hydraulic-conductivity, fine-grained sediments. The the treatment chemicals. Cationic flocculants or organic solvents ane introduced to increase the hydraulic conductivity and carmy away mobilized contaminants, including hydrophilic hydrocarbons, hydrophobic fuel hydrocarbons, and halogenated hydrocarbons.

A system that provides both a dispersion reduction and a direct detection to a receiver, with microwave mixers and lithium-niobate extemal modulators that produce sidebands separated by a few gigahert from a principal laser optical carrier. Digital data streams are independenty mode fiber. Independe sigh sseed dat streams a colve microwave frequencies. These subcariers are then combined with a microwave power combiner and amplifiec.

A detector that is focused onto a region where a projectile is expected to be located. Successive images of inffared radiation in the region are suppressed such that successive images are produced of infrared radiation generated by the projectile as the projectile passes through the of the projectile by using the successive images of infrared rader aspects generated by the projectile. The apparatus can also determine the origin of
the projectile's path and photograph and/or fire a projectile at that area. A method for forming synthetic crystals of proteins in a carrier fluid by using dipole moments of protein macromolecules that self-align in the
Helmholtz layer adjacent to an electrode. The voltage gradients of such layers exceed $106 \mathrm{~V} / \mathrm{m}$. The voltage promotes formation of the protein macromolecules into pearr chains and three-dimensional crystals. The determine than conventional methods.

1997. The Regents of the University of California. All rights reserved. This document has been authored by the The Regents of the University of Califormia under Contract No. W-7405Eng-48 with the U.S. Government. To request permission to use any material contained in this document, please submit your request in writing to the Technical Information Departmen.

This document was prepared as an account of work sponsored by an agency of the United States Government. Neither the United States Government nor the University of Califormi nor any of their employees makes any warranty, expressed or implied, or assumes any legal liability or responsibility for the accuracy, completeness, or usefuluess of any information, trade name, trademark manufacturer or otherwise, does not necessarily constitute or inply its endersement recommendation, or favoring by the United States Givernm,

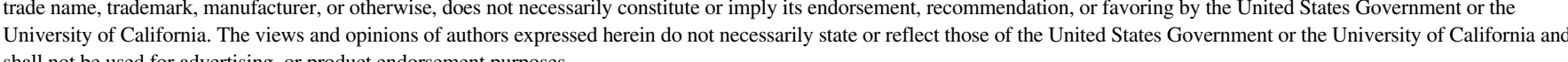
shall not be used for advertising or product endorsement purposes.

U.S. Government Printing Office: 1997/583-059-60016 